\title{
Borrelia burgdorferi sensu lato in Ixodes ricinus ticks from Norway: evaluation of a PCR test targeting the chromosomal $f l a B$ gene
}

\author{
Andrew Jenkins • Dag Hvidsten • Andreas Matussek • Per-Eric Lindgren • \\ Snorre Stuen • Bjørn-Erik Kristiansen
}

Received: 15 February 2012/Accepted: 23 May 2012/Published online: 9 June 2012

(C) The Author(s) 2012. This article is published with open access at Springerlink.com

\begin{abstract}
A consensus TaqMan real-time PCR test targeting the chromosomal flaB gene of Borrelia burgdorferi sensu lato was constructed. The test was compared with a recently published generic Light Upon eXtension (LUX) 16S rRNA real-time PCR test (Wilhelmsson et al. in J Clin Microbiol 48:4169-4176, 2010) on material consisting of 242 Ixodes ricinus ticks collected from dogs and cats in Northern Norway $(\mathrm{n}=139)$ and Telemark County in Southern Norway $(n=103)$. Ticks positive in either test were further tested by nested PCR amplification of the 5S-23S rRNA intergenic-spacer region followed by sequencing for species identification. A tick was defined as Borrelia positive if two of three tests were positive. Thirty-four of the $242(14 \%)$ ticks satisfied this definition of
\end{abstract}

A. Jenkins · B.-E. Kristiansen
Unilabs Telelab, Skien, Norway

Present Address:

A. Jenkins

Department of Environmental and Health Studies, Telemark University College, B $\emptyset$, Norway

D. Hvidsten

Department of Microbiology and Infection Control, University Hospital of North Norway, Troms $\varnothing$, Norway

A. Matussek $(\bowtie) \cdot$ P.-E. Lindgren

Clinical Microbiology Laboratory, Division of Medical Services, Department of Laboratory Medicine,

County Hospital Ryhov, 55185 Jönköping, Sweden

e-mail: andreas.matussek@1j.se

P.-E. Lindgren

Division of Medical Microbiology, Department of Clinical and Experimental Medicine,

Linköping University, Linköping, Sweden

\section{S. Stuen}

Department of Production Animal Clinical Sciences, Norwegian School of Veterinary Science,

Sandnes, Norway

B.-E. Kristiansen

Department of Microbiology and Virology, University of Troms $\emptyset$, Troms $\emptyset$, Norway 
positivity. Of these ticks 32 were positive both in the rRNA and flaB test, while two were positive only in the rRNA test. One tick was positive only in the rRNA test and was considered false positive since PCR for sequencing failed. The sensitivity of the $f a B$ test was $94 \%$ and the specificity $100 \%$. It was possible to determine the species present using Tm analysis. Among ticks from Northern Norway the prevalence of Borrelia was $13 \%$, whereas the prevalence in Telemark was $16 \%$. Among identified species $(\mathrm{n}=33)$ B. afzelii was found in $16(47 \%), B$. garinii in $15(44 \%)$ and B. valaisiana in $2(6 \%)$ ticks, respectively. The $f a B$ test is a rapid, sensitive and specific test for detection and quantification of Borrelia burgdorferi s.l. in I. ricinus ticks. This is the first report on Borrelia prevalence in I. ricinus in Northern Norway.

Keywords Lyme borreliosis - Ixodes ricinus - TaqMan real-time PCR · Norway · flaB gene $\cdot$ Prevalence $\cdot$ Borrelia burgdorferi sensu lato

\section{Introduction}

Lyme borreliosis (LB) is caused by bacteria of the Borrelia burgdorferi sensu lato (s.1.) complex, which infect through the bite of the hard tick Ixodes ricinus. Borrelia burgdorferi s.l. encompasses eighteen genospecies of which six are associated with human infections (Stanek and Reiter 2011). LB is the most common vector-borne disease in Europe, although showing great regional variation (Stanek and Strle 2003; Stanek and Reiter 2011). In Norway, ticks and LB are abundant along the southern coast. Earlier observations indicate that $I$. ricinus ticks are not endemic north of Brønnøy in Northern Norway (Tambs-Lyche 1943; Braathen et al. 1987). However, recent studies indicate that ticks may be found on dogs and cats further north (Jore et al. 2011, Meldal unpublished material), and they are believed to be imported by migrating birds (Comstedt et al. 2006; Olsen et al. 1995).

In Norway, invasive LB is a notifiable disease, and 250-350 cases are reported yearly to the National Institute of Health, with highest prevalence in the counties of Telemark, AustAgder, Vest-Agder and Møre og Romsdal. In 2001 Jenkins et al. found Borrelia ssp. in $16 \%$ of the ticks on an island in the southern part of Telemark. A prevalence of $25 \%$ of $B$. burgdorferi s.l. in questing nymphal and adult ticks was recently demonstrated in the southernmost county in Norway (Kjelland et al. 2010).

Recently, several PCR based methods have been developed for analysis of Borrelia spp. in clinical samples and ticks (Ivacic et al. 2007; Wilhelmsson et al. 2010). Speed, sensitivity and the possibility of species typing and quantification of Borrelia spp. are major advantages of PCR based molecular methods. The introduction of real-time PCR technologies has further reduced analysis times and improved reliability by eliminating the problem of carry-over contamination.

Consensus PCR tests offer an attractive approach for the detection of various $B$. burgdorferi s.l. spp. in ticks. Design of such assays presupposes genes that are ubiquitous in Borrelia spp. and well sequenced such as ospA (Ivacic et al. 2007) and the 16S rRNA gene (Wilhelmsson et al. 2010).

In this study, we developed and evaluated a consensus TaqMan real-time PCR test targeting a third well sequenced gene, $f a B$, for the detection and quantification of $B$. burgdorferi s.l. The evaluation was performed through analysis of B. burgdorferi s.l. present in I. ricinus ticks collected from dogs and cats from the northern and southern part of Norway. Results from our developed test were compared with results obtained using a Light Upon eXtension (LUX) 16S rRNA test (Wilhelmsson et al. 2010). Confirmation of 
PCR results and species determination was performed by sequencing of the 5S-23S rRNA intergenic-spacer (IGS) region (Postic et al. 1994).

\section{Materials and methods}

Collection of ticks and microscopy

Twenty-three veterinarians in the three northernmost counties in Norway, i.e. Nordland, Troms and Finnmark (from $65^{\circ} 29^{\prime} \mathrm{N} ; 12^{\circ} 14^{\prime} \mathrm{E}$ to $70^{\circ} 12^{\prime} \mathrm{N} ; 28^{\circ} 10^{\prime} \mathrm{E}$ ), and five in the southeastern county Telemark (from $58^{\circ} 53^{\prime} \mathrm{N} ; 9^{\circ} 17^{\prime} \mathrm{E}$ to $59^{\circ} 59^{\prime} \mathrm{N} ; 8^{\circ} 43^{\prime} \mathrm{E}$ ), collected ticks from dogs and cats. The ticks were placed in plastic tubes containing $3 \mathrm{ml} 70 \%$ ethanol and sent to the microbiology laboratory for further analysis. The collected ticks were examined by light microscopy.

Preparation of reverse-transcribed total nucleic acid from ticks

Before nucleic acid (NA) extraction ethanol was decanted, $450 \mu \mathrm{l}$ RLT lysis buffer (Qiagen, Hilden, Germany) containing $1 \%$ vol/vol $\beta$-mercaptoethanol was added into the tube. Tubes were then frozen for $1 \mathrm{~h}$ at $-180{ }^{\circ} \mathrm{C}$ (Crampton et al. 1996) and thawed at room temperature. Disruption was performed by bead beating ( $25 \mathrm{~Hz}$ for $2 \mathrm{~min}$ ) with a $5 \mathrm{~mm}$ stainless steel bead in a TissueLyserII instrument (Qiagen), according to the manufacturer's instructions. After centrifugation at $20,000 \mathrm{~g}$ for $3 \mathrm{~min}, 400 \mu \mathrm{l}$ of the supernatant was used for NA extraction. Total NA purification was then performed in a M48 instrument (Qiagen) using the MagAttract RNA Tissue Mini M48 Kit without the DNase step, according to the protocol of the manufacturer, and eluted in $50 \mu \mathrm{l}$ of the supplied buffer.

Synthesis of cDNA was performed in a PALM PCR cycler (Corbett Research, Australia) using the Illustra Ready-to-Go RT-PCR Beads kit (GE Healthcare Bio-Sciences AB, Stockholm, Sweden). Fifteen $\mu \mathrm{l}$ purified total NA, $2.5 \mu \mathrm{g}$ random hexamer primers and one bead were incubated in a total volume of $50 \mu \mathrm{l}$ for $30 \mathrm{~min}$ at $42{ }^{\circ} \mathrm{C}$. The enzymatic reaction was stopped at $95{ }^{\circ} \mathrm{C}$ for $5 \mathrm{~min}$. cDNA products were stored at $-20{ }^{\circ} \mathrm{C}$.

\section{Borrelia flaB PCR}

Borrelia burgdorferi s.l. flaB sequences showing $>90 \%$ homology to $B$. valaisiana DQ111037 were identified by BLAST search and downloaded. After screening out identical sequence replicates CLUSTAL alignments were performed and displayed with BOXSHADE. To keep alignments to a manageable size, the sequences were grouped into four subsets of 50-60 sequences. The resulting consensus sequences were edited manually to reflect the full range of sequence variation and a new alignment using the edited consensus sequences was performed. This led to the identification of a region sufficiently conserved for design of consensus primers. Primer and probe design was performed using Primer Express (Applied Biosystems, Foster City, CA) with B. burgdorferi X16833 as input sequence. Variant positions were accommodated by use of the noncanonical G:T basepair, a G/C degeneracy in the forward primer and two probe sequences. Primers, probes and target sequences are shown in Fig. 1 and Table 1. It should be noted that no sequence information for the target region is available for B. americana, B. bissettii, 


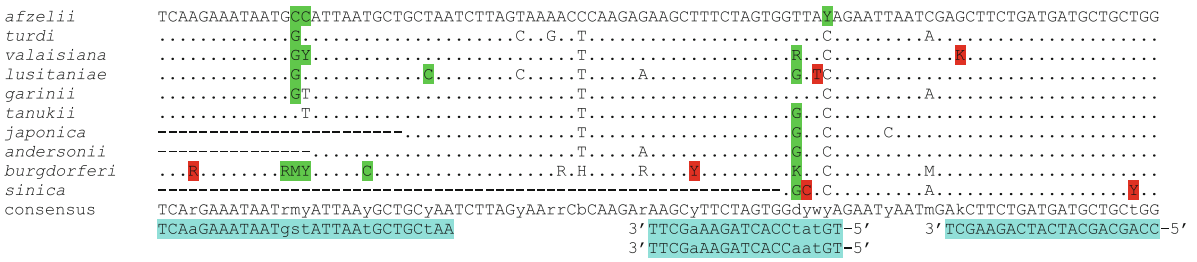

Fig. 1 Multiple sequence alignment of target, primer and probe sequences. Dots indicated identity to the reference sequence. Hyphens indicate regions where no sequence information is available. The following IUPAC ambiguity codes are used: $\mathrm{Y}=\mathrm{T} / \mathrm{C} ; \mathrm{R}=\mathrm{A} / \mathrm{G} ; \mathrm{M}=\mathrm{A} / \mathrm{C} ; \mathrm{S}=\mathrm{G} / \mathrm{C} ; \mathrm{H}=\mathrm{A} / \mathrm{C} / \mathrm{T} ; \mathrm{K}=\mathrm{G} / \mathrm{T}$; $\mathrm{D}=\mathrm{A} / \mathrm{G} / \mathrm{T} ; \mathrm{B}=\mathrm{C} / \mathrm{T} / \mathrm{G}$. Variant positions are indicated by lower case letters in the consensus and primer/ probe sequences. Variants accommodated by G:T basepairing or degeneracy of the primer/probe sequence are highlighted in green in the target sequence. Variants not so accommodated are highlighted in red. Primer and probe sequences are highlighted in blue. Unless otherwise noted, sequences are written 5' - 3'. (Color figure online)

Table 1 Primer/probe sequences for $f l a B$ PCR

\begin{tabular}{llll}
\hline Name & Function & Sequence & Tm \\
\hline FlaBf & Forward primer & TCAAGAAATAATGSTATTAATGCTGCTAA ${ }^{\mathrm{a}}$ & $58.8 / 59$ \\
$\mathrm{FlaBr}$ & Reverse primer & CCAGCAGCATCATCAGAAGCT & 59.2 \\
FlaBmA & Probe & TGTATCCACTAGAAAGCTT & 69.5 \\
FlaBm3B & Probe & TGTAACCACTAGAAAGCTT & 69.7 \\
\hline
\end{tabular}

${ }^{a} \mathrm{~S}=\mathrm{C}+\mathrm{G}$

B. californiensis, B. carolinensis, B. spielmanii, B. kurtzenbachii or B. yangtze (Stanek and Reiter 2011). Primers were obtained from Genscript Corporation (Piscataway, NJ). TaqMan MGB probes labelled with VIC were obtained from Applied Biosystems. Primer and probe concentrations were optimised leading to the following PCR conditions: $600 \mathrm{nM}$ each primer, $75 \mathrm{nM}$ each probe, $5 \mu \mathrm{l}$ sample, and Finnzymes DyNAmo Probe qPCR mastermix with ROX (Thermo Fischer Scientific, Vantaa, Finland), reaction volume $25 \mu \mathrm{l}$. The PCR program was $50{ }^{\circ} \mathrm{C}, 2 \mathrm{~min} ; 95{ }^{\circ} \mathrm{C}, 10 \mathrm{~min}$ followed by 40 cycles of $95{ }^{\circ} \mathrm{C}, 15 \mathrm{~s}$; $60{ }^{\circ} \mathrm{C} 1 \mathrm{~min}$. For Tm determination the same PCR program, followed by dissociation analysis was performed, using Finnzymes DyNAmo SYBR-green qPCR mastermix (Thermo Fischer Scientific).

To provide control DNA of known concentration, a synthetic plasmid, pFLA, comprised of nucleotides 1-210 from the B. burgdorferi flaB sequence X15661 cloned in pUC59 was obtained from Genscript Corporation. This was used to determine analytical sensitivity. Plasmid DNA was serially diluted in a $10 \mathrm{ng} / \mu \mathrm{l}$ solution of purified human genomic DNA (Sigma Aldrich, St Louis, MI) in TE buffer. The limit of detection (Bustin et al. 2009) was determined by testing ten replicates of the lowest and next-lowest detectable dilutions. 10/10 $300 \mathrm{GU}$ replicates and 7/10 $30 \mathrm{GU}$ replicates were positive. The limit of detection is thus nominally $300 \mathrm{GU}$.

LUX 16S rRNA real-time PCR test and species identification

The LUX 16S rRNA real-time PCR test for Borrelia spp. analysis was performed according to Wilhelmsson et al. (2010). Briefly, PCR was carried out in 96-well reaction plates (Applied Biosystems), and the $20 \mu \mathrm{l}$ reaction mixture used contained $10 \mu \mathrm{l}$ 
Platinum ${ }^{\circledR}$ qPCR SuperMix UDG (Invitrogen, Carlsbad, CA), $0.04 \mu \mathrm{l}$ Rox reference (Invitrogen), $0.4 \mu \mathrm{l}$ LUXTM Bor16SFL primer $(10 \mu \mathrm{M}), 0.4 \mu \mathrm{l}$ unlabeled Bor16SR primer $(10 \mu \mathrm{M})$ (TIB MOLBIOL, Berlin, Germany), $7.16 \mu \mathrm{l}$ RNAse free water and $2 \mu \mathrm{l}$ of template, using an ABI PRISM 7500 Fast Real-Time PCR System (Applied Biosystems). The following reaction conditions were applied, $50{ }^{\circ} \mathrm{C}$ for $2 \mathrm{~min}$ for the UDG reaction, $95{ }^{\circ} \mathrm{C}$ for $2 \mathrm{~min}$ for polymerase activation, and then 45 cycles of $95{ }^{\circ} \mathrm{C}$ for $15 \mathrm{~s}, 58{ }^{\circ} \mathrm{C}$ for $30 \mathrm{~s}$ and $72{ }^{\circ} \mathrm{C}$ for $30 \mathrm{~s}$. Melting curve analysis was performed by heating to $95{ }^{\circ} \mathrm{C}$ for $15 \mathrm{~s}$, followed by cooling to $60^{\circ} \mathrm{C}$ for $1 \mathrm{~min}$ and subsequent heating to $95{ }^{\circ} \mathrm{C}$ at $0.8^{\circ} \mathrm{C}$ per minute with continuous fluorescence recording.

A nested PCR approach was used to amplify the IGS region for species typing, using a PALM PCR cycler (Corbett Research, Australia) (Postic et al. 1994). A final volume of $50 \mu \mathrm{l}$ reaction mixture, containing $5 \mu \mathrm{l}$ of $10 \times$ PCR buffer, $1 \mu \mathrm{l}$ of deoxyribonucleotide triphosphate $(10 \mathrm{mM}), 1 \mu \mathrm{l}$ each of the primers 5S-23SF and 5S-23SR $(10 \mu \mathrm{M})$ (Table 1), $0.38 \mu \mathrm{l}$ of High Fidelity polymerase $(3.5 \mathrm{U} / \mu \mathrm{l})$ (Amersham Biosciences, Uppsala, Sweden), $5 \mu \mathrm{l}$ template DNA (2-4 ng/ $\mu \mathrm{l})$ and $36.62 \mu \mathrm{l}$ of RNase-free water was used. The amplification program consisted of heating at $95{ }^{\circ} \mathrm{C}$ for $5 \mathrm{~min}$, followed by $95{ }^{\circ} \mathrm{C}$ for $15 \mathrm{~s}$, $57{ }^{\circ} \mathrm{C}$ for $30 \mathrm{~s}, 72{ }^{\circ} \mathrm{C}$ for $30 \mathrm{~s}$ for 39 cycles and finally $72{ }^{\circ} \mathrm{C}$ for $7 \mathrm{~min}$. Five $\mu \mathrm{l}$ of the PCR-product was added to the second PCR reaction mixture with the same volumes, concentrations and amplification programs as the first, using other primers (Bor5S-23SFn and Bor5S-23SRn) and running for 42 cycles (Postic et al. 1994).

Nucleotide sequencing of the PCR-products obtained was performed by GATC (Biotech, Konstanz, Germany). DNA chromatograms were analyzed using the RipSeq web application (iSentio, Bergen, Norway), which allows analysis for a single species as well as mixed samples containing up to three different species (Kommedal et al. 2009).

\section{Definitions and statistical methods}

Definitions: A positive result: when the sample is positive in both PCR tests, or positive in one PCR test and confirmed by sequencing of the 5S-23S rRNA IGS region. A negative result: when negative in both tests, or negative in one PCR and positive in the other, and in addition no PCR product was revealed from the 5S-23S rRNA IGS region.

The kappa statistic was calculated as described in Fleiss et al. (2003).

\section{Results}

All ticks collected were engorged female $I$. ricinus. In total, 242 ticks were collected from $\operatorname{dogs}(n=222)$ and cats $(n=20)$. Ticks were more abundant in Telemark than in Northern Norway, however, Brønnøy, situated in the southern part of Northern Norway, displayed high tick abundance (33 ticks found on 19 dogs) (Table 2).

Among 28 dogs that harboured more than one tick, only two dogs had more than one Borrelia positive tick (data not shown).

Evaluation of the PCR assay targeting the $f l a B$

A total of 32 ticks were Borrelia positive in both real-time PCR tests used, and 207 out of 242 ticks were negative in both tests. Three ticks were only reactive in the rRNA test, kappa $=0.93$. All three discrepant ticks had high $\mathrm{Cq}$ values $(>35)$, indicative of low concentrations of Borrelia NA. In two of these ticks sequencing for species identification 
Table 2 Borrelia ssp. positive Ixodes ricinus ticks in dogs and cats from veterinary clinics in the county of Telemark and the counties of Northern Norway

\begin{tabular}{lllllllll}
\hline Counties & $\begin{array}{l}\text { Veterinary } \\
\text { clinics, } \\
\mathrm{n}\end{array}$ & $\begin{array}{l}\text { Pets, } \\
\mathrm{n}\end{array}$ & $\begin{array}{l}\text { Ticks, } \\
\mathrm{n}\end{array}$ & $\begin{array}{l}\text { Ticks/ } \\
\mathrm{p} \text { t, } \\
\mathrm{n}\end{array}$ & $\begin{array}{l}\text { Borrelia } \\
\text { positive, n }(\%)\end{array}$ & $\begin{array}{l}\text { B. afzelii, } \\
\mathrm{n}(\%)\end{array}$ & $\begin{array}{l}\text { B. garinii, } \\
\mathrm{n}(\%)\end{array}$ & $\begin{array}{l}\text { B. valaisiana, } \\
\mathrm{n}(\%)\end{array}$ \\
\hline $\begin{array}{l}\text { N. Norway ex. } \\
\text { Brønnøy }\end{array}$ & 17 & 94 & 106 & 1.1 & $10^{1}(9)$ & $5(50)$ & $4(40)$ & $0(0)$ \\
$\begin{array}{l}\text { Brønnøy } \\
\text { Telemark }\end{array}$ & 1 & 19 & 33 & 1.7 & $8(24)$ & $3(38)$ & $4(50)$ & $1(13)$ \\
Totals & 5 & 71 & 103 & 1.5 & $16(16)$ & $8(50)$ & $7(44)$ & $1(6)$ \\
\hline
\end{tabular}

1 In one tick, the Borrelia genospecies could not be determined

was successful. One Borrelia reactive tick was considered false positive since sequencing of the 5S-23S rRNA IGS region failed. According to our definitions 34 ticks were therefore considered Borrelia spp. positive, whereas one tick showed a false positive result in the rRNA test. Altogether, the rRNA test detected all true Borrelia spp. positive ticks, while the newly developed assay failed to detect two positive ticks, reaching a sensitivity of $94 \%$. The specificity for the developed test was $100 \%$.

Figure 2 shows a comparison of cycle threshold $(\mathrm{Cq})$ values obtained with the $f l a B$ and rRNA tests.

Borrelia species and geographical distribution

The prevalence of Borrelia positive ticks in Telemark was $16 \%$ (16 of 103) and in Northern Norway $13 \%$ (18 of 139), including the municipality of Brønnøy with a prevalence of $24 \%$ (8 of 33) (Table 2 and Fig. 3).

Sequencing $(\mathrm{n}=33)$ of the 5S-23S rRNA IGS region identified B. afzelii in $16(47 \%)$, $B$. garinii in $15(44 \%)$ and $B$. valaisiana in two (6\%) ticks, respectively. Mixed sequences were not found.

Dissociation analysis of the $f a B$ product yielded Tm data for 21 ticks. Ticks containing B. afzelii $(\mathrm{n}=12), B$. garinii $(\mathrm{n}=8)$ and B. valaisiana $(\mathrm{n}=1)$ showed dissociation peaks at $74.1 \pm 0.5,72.9 \pm 0.4$ and $77.3^{\circ} \mathrm{C}$, respectively. Nine ticks showed multiple dissociation peaks.

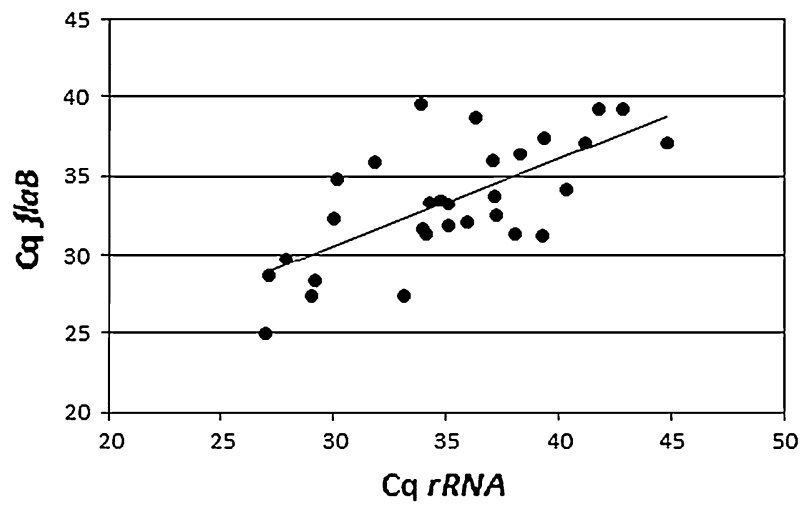

Fig. 2 Comparison of Cq values for rRNA-LUX and TaqMan-flaB PCR. The slope is $\mathrm{y}=0.90 \mathrm{x}+4.5$ and the correlation coefficient $\left(r^{2}\right)$ is 0.47 


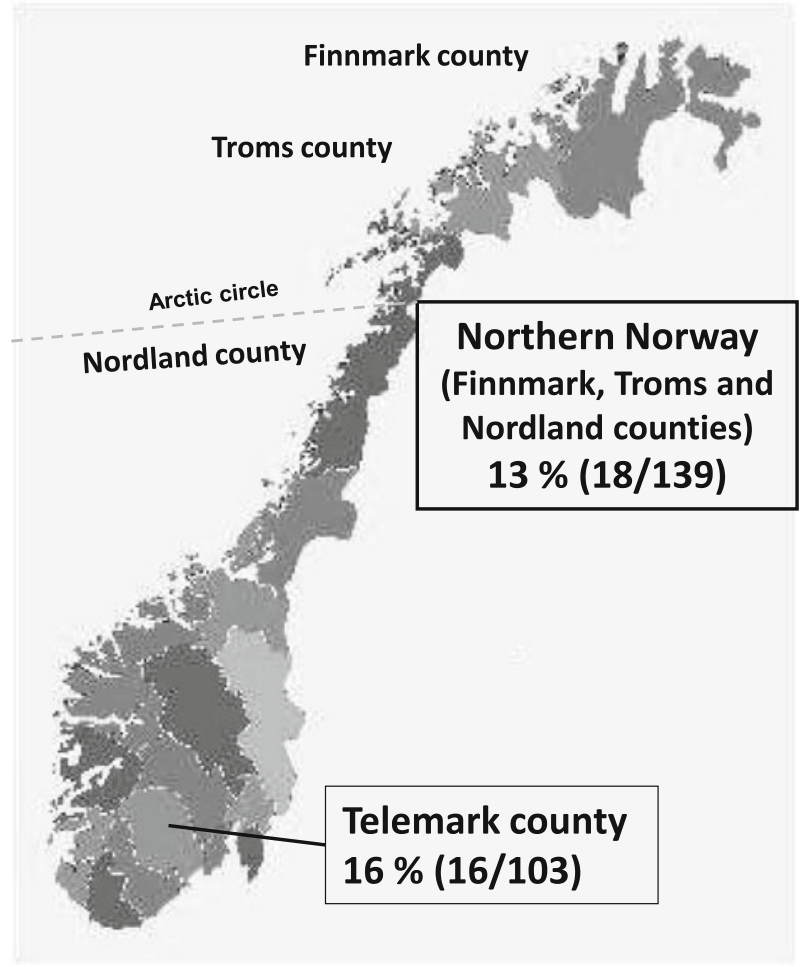

Fig. 3 Borrelia spp. prevalence in Ixodes ricinus ticks in Northern Norway and Telemark

\section{Discussion}

In the present study, we compare our new TaqMan real-time PCR test targeting the flaB with a LUX based real-time PCR test targeting the 16S rRNA gene (Wilhelmsson et al. 2010), for detection and quantification of B. burgdorferi s.l. in I. ricinus ticks. In addition, we present preliminary epidemiological data regarding prevalence and species distribution of Borrelia in ticks collected from dogs and cats from different parts of Norway.

The developed test was specific but apparently less sensitive than the rRNA test. The difference in sensitivity is not unexpected as the rRNA PCR test targets a very abundant RNA molecule and is also five PCR cycles longer. In the cases where the $f l a B$ test gave a false negative result, the rRNA test had a high $\mathrm{Cq}$ value, indicative of weakly positive samples. Mismatch to primers or probes is not likely to have caused the discrepancies as neither of the species present, B. afzelii and B. garinii has sequence variants expected to compromise the sensitivity of flaB PCR.

The rRNA PCR test is a broad-specificity test designed to detect all Borrelia spp, including the relapsing fever Borreliae. The flaB PCR test is designed to detect B. burgdorferi s.l. species. On the basis of sequence mismatches (see Fig. 1) the flaB test may have reduced sensitivity for $B$. sinica, $B$. lusitaniae, and certain variants of B. burgdorferi sensu stricto and $B$. valaisiana, while sequence information for the target region is unavailable for B. americana, B. bissettii, B. californiensis, B. carolinensis, B. kurtzenbachii, B. spielmanii, and B. yangtze; and incomplete for B. japonica, B. andersonii and B. sinica. Of 
these species, only $B$. valaisiana occurs in the present material. Thus, a more diverse sample material will be required to completely evaluate the $f a B$ test. The 48 bp region between the $f l a B$ primers contains sequence differences which may be revealed by $\mathrm{T}_{\mathrm{m}}$ analysis. The presence of $B$. afzelii, $B$. garinii and $B$. valaisiana corresponded to melting peaks of 74,73 and $77{ }^{\circ} \mathrm{C}$, respectively. Hence, our results indicate that Tm analysis of the $f a B$ PCR provides a rapid and accurate indication of the Borrelia species present, although this has to be assessed on a broader range of Borrelia species. In addition, the significance of multiple peaks has to be investigated.

Borrelia prevalence in engorged female ticks from Telemark was similar to findings in questing ticks in an earlier investigation from the same county (Jenkins et al. 2001). We had no information from the pet owners whether the ticks were located in close proximity to each other. However, in 28 pets that harboured more than one tick, only two dogs had more than one Borrelia positive tick. Hence, co-feeding transmission has not influenced the number of Borrelia positive ticks.

Generally, there are more pets with ticks and more ticks per pet seen by the veterinarians in Telemark than in Northern Norway (Table 2).

However, in the municipality of Brønnøy the veterinarian found on average 1.7 ticks per dog, which is even a higher figure than in Telemark. Furthermore, a high proportion (24\%) of the included ticks in Brønnøy were positive for Borrelia spp. (Table 2).

In the present study, B. afzelii, B. garinii and B. valaisiana were found in $47 \%, 44 \%$ and $6 \%$ of ticks respectively. This distribution differ from recent data including ticks that have bitten humans in Sweden, where B. afzelii was present in over $60 \%$ and B. garinii in $23 \%$, respectively (Wilhelmsson et al. 2010). However, our data follow the same Borrelia spp. pattern demonstrated in questing adults and nymphal ticks in South Norway (Kjelland et al. 2010).

This is the first report investigating Borrelia in ticks collected in Northern Norway. Future studies are needed, using strict criteria regarding for instance stays outside the county of residence, and a larger population of ticks collected from pets, for a better understanding of the Borrelia epidemiology in different parts of Norway.

In summary, we have developed a robust, sensitive, specific and rapid PCR test based on $f l a B$ for detection and quantification of B. burgdorferi s.l. with the possibility of rapid species subtyping. Our data give new insights into Norwegian Borrelia epidemiology.

Acknowledgments We gratefully acknowledge the contributions of Randi Aakre, Anne-Gry Allum, Charlotte Bøydler, Olaf Dienus and Peter Wilhelmsson who performed the laboratory work and of Reidar Mehl, who performed microscopy. We also thank the personnel at the veterinary clinics in Northern Norway and Telemark that examined the pets and collected the ticks.

Open Access This article is distributed under the terms of the Creative Commons Attribution License which permits any use, distribution, and reproduction in any medium, provided the original author(s) and the source are credited.

\section{References}

Braathen LR, Austad J, Mork NJ, Holm JO, Mehl R (1987) Chronic erythema migrans and chronic acrodermatitis atrophicans. Tick-borne Borrelia spirochete infections of the skin. Tidsskrift for den Norske laegeforening : tidsskrift for praktisk medicin, ny raekke 107:1649-1651

Bustin SA, Benes V, Garson JA, Hellemans J, Huggett J, Kubista M, Mueller R, Nolan T, Pfaffl MW, Shipley GL, Vandesompele J, Wittwer CT (2009) The MIQE guidelines: minimum information for publication of quantitative real-time PCR experiments. Clin Chem 55:611-622 
Comstedt P, Bergstrom S, Olsen B, Garpmo U, Marjavaara L, Mejlon H, Barbour AG, Bunikis J (2006) Migratory passerine birds as reservoirs of Lyme borreliosis in Europe. Emerg Infect Dis 12:1087-1095

Crampton A, McKay I, Barker SC (1996) Phylogeny of ticks (Ixodida) inferred from nuclear ribosomal DNA. Int J Parasitol 26:511-517

Fleiss JL, Levin BA, Paik MC (2003) Statistical methods for rates and proportions [Elektronisk resurs]. Wiley, Hoboken

Ivacic L, Reed KD, Mitchell PD, Ghebranious N (2007) A LightCycler TaqMan assay for detection of Borrelia burgdorferi sensu lato in clinical samples. Diagn Microbiol Infect Dis 57:137-143

Jenkins A, Kristiansen BE, Allum AG, Aakre RK, Strand L, Kleveland EJ, van de Pol I, Schouls L (2001) Borrelia burgdorferi sensu lato and Ehrlichia spp. in Ixodes ticks from southern Norway. J Clin Microbiol 39:3666-3671

Jore S, Viljugrein H, Hofshagen M, Brun-Hansen H, Kristoffersen AB, Nygard K, Brun E, Ottesen P, Saevik BK, Ytrehus B (2011) Multi-source analysis reveals latitudinal and altitudinal shifts in range of Ixodes ricinus at its northern distribution limit. Parasites Vectors 4:84

Kjelland V, Stuen S, Skarpaas T, Slettan A (2010) Borrelia burgdorferi sensu lato in Ixodes ricinus ticks collected from migratory birds in Southern Norway. Acta Vet Scand 52:59

Kommedal O, Kvello K, Skjastad R, Langeland N, Wiker HG (2009) Direct 16S rRNA gene sequencing from clinical specimens, with special focus on polybacterial samples and interpretation of mixed DNA chromatograms. J Clin Microbiol 47:3562-3568

Olsen B, Duffy DC, Jaenson TG, Gylfe A, Bonnedahl J, Bergstrom S (1995) Transhemispheric exchange of Lyme disease spirochetes by seabirds. J Clin Microbiol 33:3270-3274

Postic D, Assous MV, Grimont PA, Baranton G (1994) Diversity of Borrelia burgdorferi sensu lato evidenced by restriction fragment length polymorphism of $\operatorname{rrf}(5 \mathrm{~S})$-rrl (23S) intergenic spacer amplicons. Int J Syst Bacteriol 44:743-752

Stanek G, Reiter M (2011) The expanding Lyme Borrelia complex-clinical significance of genomic species? Clin Microbiol Infect Off Publ Eur SocClin Microbiol Infect Dis 17:487-493

Stanek G, Strle F (2003) Lyme borreliosis. Lancet 362:1639-1647

Tambs-Lyche H (1943) Ixodes ricinus og piroplasmosen i Norge. Norsk veterinærtidsskrift. 55:337-366 [401-441, 449-506, 513-552]

Wilhelmsson P, Fryland L, Borjesson S, Nordgren J, Bergstrom S, Ernerudh J, Forsberg P, Lindgren PE (2010) Prevalence and diversity of Borrelia species in ticks that have bitten humans in Sweden. J Clin Microbiol 48:4169-4176 